\title{
Recollections on the Development of Interventional Radiology in the United States
}

\author{
Harold A. Mitty ${ }^{1}$ \\ ${ }^{1}$ Department of Radiology, Icahn School of Medicine at Mount Sinai, \\ New York, New York, United States \\ J Clin Interv Radiol ISVIR 2017;1:69-70.
}

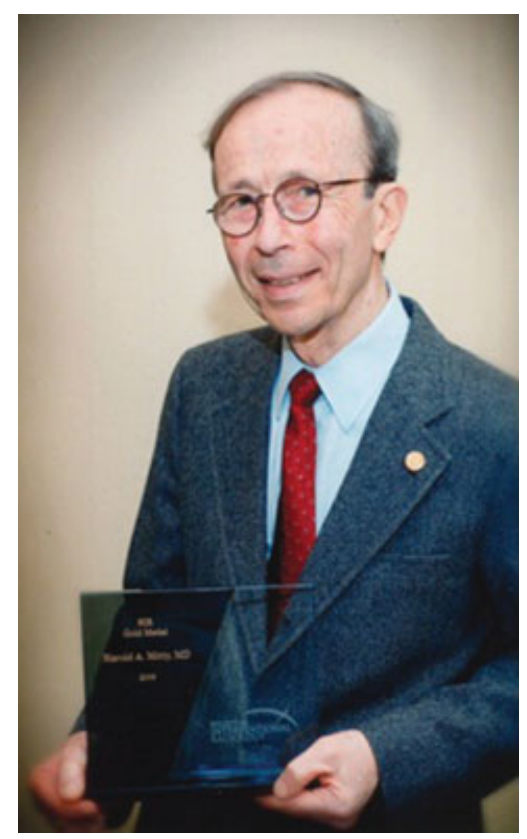

Fig. 1 Photo of author receiving gold medal of the Society of Interventional Radiology in 2006.

Although we now think of the national and international development of organized interventional radiology, it is important to remember that some of the early beginnings were in local "angio clubs." These clubs often had different formats such as case presentations, formal papers, and lectures, or combinations of these elements. There were also regional angio groups that eventually became part of the national society. The terminology interventional radiology was suggested by Dr Margulis.,

\section{New York City Angio Club}

In an effort to foster professional development, there were a variety of radiology clubs dealing with bone, chest, pedia-
Address for correspondence Harold A. Mitty, MD, FACR, FSIR, Icahn School of Medicine at Mount Sinai, 1 Gustave L. Levy Place, New York, NY 10029-5674, United States (e-mail: haroldmitty@gmail.com).

trics, neurology, and angiography that met in New York City (NYC). These evening meetings were generally informal case presentations, often leading to lively discussions. The meetings usually rotated between Manhattan hospitals, although several groups chose a permanent location. The central location of Mount Sinai Hospital explains the reason it became the home of the NYC Angio Club.

The New York club was almost exclusively a case presentation format. Since there were no fellowship programs in the early days, the cases were presented by the attending radiologist who actually did the case. One might present a great triumph at one meeting and a major complication a month later. Needless to say, the meetings were not open to vendors or other nonphysicians.

The early meetings dealt with basic issues such as catheter shapes and methods of entering vessels and their branches. In the 1960s, we made most of our own catheters from a roll of catheter material that was purchased in bulk. Personal experience in catheter shaping was important since commercial catheters were not available until the 1970s.

These clubs led to sharing of case material so that more meaningful papers could be published. The friendships from these small closed meetings led to professional development since cooperation at meetings and research were more easily facilitated.

Approximately one-third of the early meetings dealt with angiocardiography. As time went on, less and less of these studies involved radiologists, so this was no longer a topic for discussion at these local meetings.

There were many memorable presentations at these meetings, some of which were startling even in retrospect. One of the first angiograms of a dissecting aneurysm was presented with just an anteroposterior (AP) view. The presenter was admonished for not having done an oblique or lateral view. His response was that he was too tired. When asked how he could be so tired as to not do a more complete study on so interesting a problem, he responded: "The patient's heart had stopped so they opened the chest in the angio room. I manually compressed the heart to get the 
AP view but didn't have enough strength left to do an additional view."

When the early reports of interventions to control bleeding by infusion of vasopressin were followed by embolization therapy, the NYC angio club really became the interventional club. Percutaneous procedures including nephrostomies, biliary drainages, and abscess drainage joined the list of vascular interventions. The proliferation of angioplasty balloons and other devices including stents added to the armamentarium of a rapidly growing specialty.

\section{Northeastern Angiography Society}

Since New York, Boston, and Philadelphia were close and blessed with good transportation, it seemed like a worthwhile idea to have yearly joint meetings. These meetings rotated between these three cities. The presentations were more formal, often consisting of papers that were to be presented at national meetings. Although these meetings were worthwhile, problems with scheduling and the rise of the Society of Cardiovascular and Interventional Radiology (SCVIR) as a national meeting led to the demise of this north eastern society.

\section{Society of Interventional Radiology}

Informal discussions about the need for a national society began in $1973 .^{3}$ The first meeting of the 48 founding members took place in Key Largo, Florida. Even at this early date, we presented brief papers. It was decided to name the organization Society of Cardiovascular Radiology (SCVR). New members were to have published and were to be voted on in closed sessions. One of the early bylaws described the organization as made up of radiologists. When this was presented at our meeting, one hand went up to object. It was Dr. Constantine Cope, one of the nation's most respected angiographers. He informed the group that he was in fact an internist by training and certification. That problem was quickly remedied.
Some of the other early nonradiologist contributors included Dr. Scott Boley, a surgeon from Montefiore Hospital in New York. He popularized the concept of nonocclusive mesenteric ischemia.

The early meetings of the national society were a two-part affair: (1) A closed meeting of the members (there was no fellow designation), usually consisting of 30 to 50 people, where projects and new ideas were hotly debated. This meeting was held in a venue separate from part (2): a course open to the physician public. The course generated enough money to cover the expenses of the SCVR members.

It became apparent that the society needed political clout to handle turf issues, compensation and billing problems, and training fellowship development. This led to the formation of members and fellows. The requirements for membership were minimal and allowed rapid growth of the SCVR. The society's name was changed to the Society of Cardiovascular and Interventional Radiology (SCVIR) in 1983. The shorter name Society of Interventional Radiology (SIR) was adopted in 2002 to reflect more accurately on the nature of daily procedures.

Fellowship programs began to develop at larger academic centers. When the Accreditation Council for Graduate Medical Education began to certify radiology fellowship programs, the American Board of Radiology decided to offer a Certificate of Added Qualification in interventional radiology, the emergence of a true specialty became apparent. The recent certification of a separate interventional radiology residency program is changing the face of training yet again.

\footnotetext{
References

1 Margulis AR. Interventional diagnostic radiology-a new subspecialty. AJR Am J Roentgenol 1967;99:761-762

2 Margulis AR. Some new approaches to the examination of the gastrointestinal tract. Hickey Lecture. AJR Am J Roentgenol 1967; 101:viii-286

3 Selby JB Jr, Darcy MD, Smith TP, Kaufman JA, Kim HS. Evolution of a specialty: the case for the association of chiefs of interventional radiology. Semin Intervent Radiol 2014;31(02):107-110
} 